\title{
The Fifth Province Approach as a Systemic Meditative Practice
}

Murmurations:

Journal of

Transformative

Systemic

Practice

\author{
Imelda McCarthy and Jean Minogue
}

\section{Volume 2}

Issue 2

Winter 2019

Keywords:

systemic therapy,

systemic

meditative

practice, unity,

emergence

Citation Link

\section{Abstract}

In this paper we want to share our experience of using systemic practices from a systemic Fifth Province Approach in the facilitation of meditation groups and retreats. We refer to our way of being and doing as a "Fifth Province Systemic Meditative Practice". The practices and approach we will present can be likened to a kind of human murmuration, where surprising, generative, inter/intra-active and relational processes emerge. These emergent processes or transformations occur spontaneously and are from within the subtle, communicative, behaviour and relational aspects of the whole group. It is in this context that we use the word "intrarelational" after the work of Karen Barad (2007 p.33). The term "subtle" refers to all the non-verbal emergences occurring from the spiritual, mental, emotional, behavioural and social processes at play.

\section{Introduction}

Imelda set the meditation group up twenty years ago and has facilitated it more or less since then. Jean facilitates the group from time to time and has, along with Imelda enjoyed tracing and noting both the practices and the emergent processes over time. Indeed, her Master's in Spirituality examined those processes and explored how they could be learned and applied in a group or individual setting. (Minogue 2018)

\section{The Fifth Province}

In beginning our story, we will start with outlining the myth and metaphor of the Fifth Province. Some of you will know something of this ancient Irish myth, that Imelda and her colleagues in the Fifth Province Associates (Nollaig Byrne and Phil Kearney) have practiced and written about since the 1980s. It is not known whether this province actually existed or not as its only trace is in the Irish language and in some Irish myths and stories. The Irish or Gaelic word for "province" means "fifth". However, in the modern-day Island of Ireland we only have four geographical provinces! So, where is this "fifth" province? Myth has it that it was to be found in 
the centre of Ireland on the Hill of Uisneach or the Hill of the Kings which is in the middle of the country.

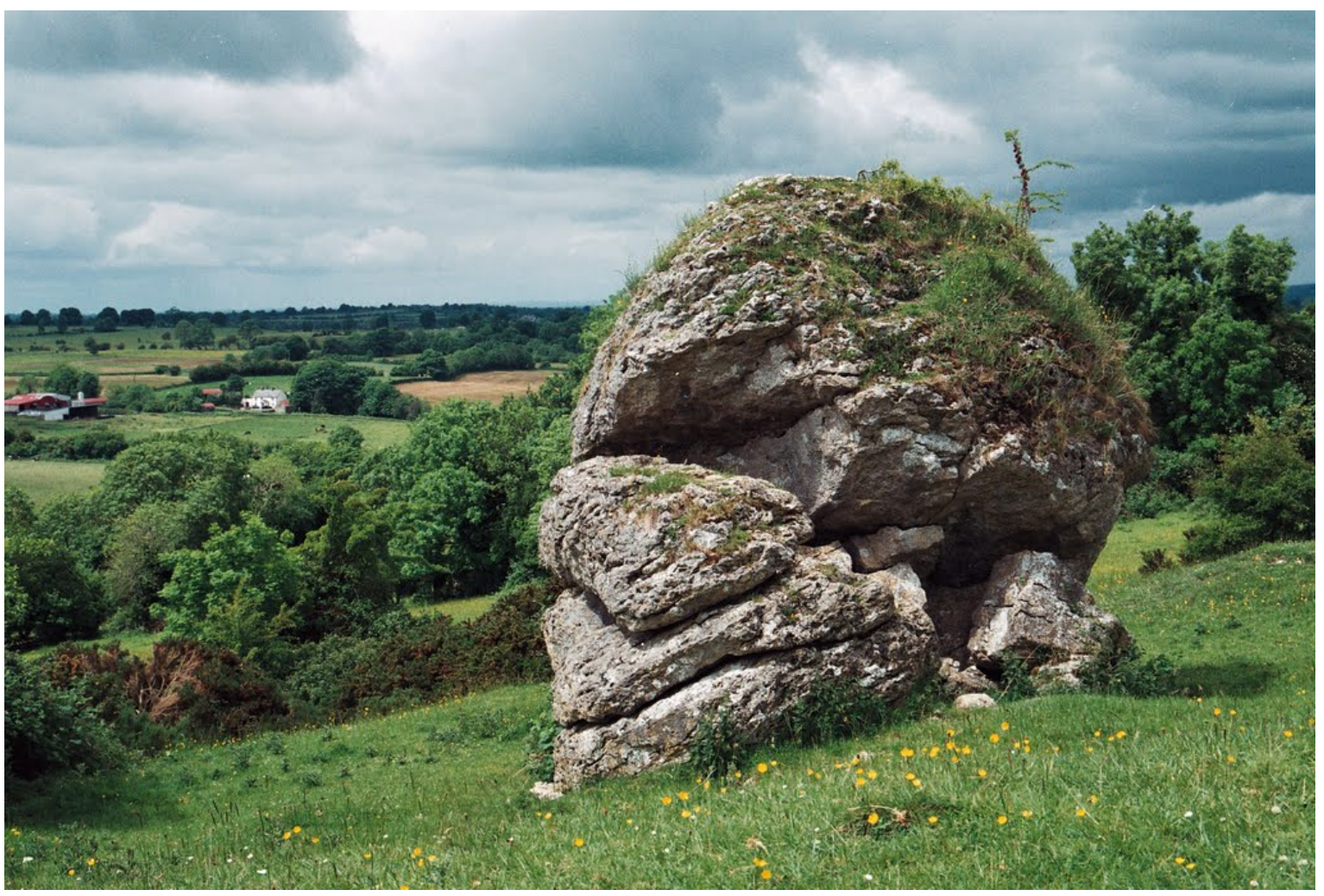

The Catstone on the Hill of Uisneach. Co. Westmeath. Ireland

At the Catstone on the hill it is said that the four ancient provinces of Ireland met. Uisneach was a Druidic site and the story is that Kings and chieftains from all over Ireland came there to receive counsel from Druids who were the priests and priestesses of the time. It was imagined that arms were left aside, and conversation became the medium of peaceful counsel and conflict resolution.

In the work of the Fifth Province Associates team (see imeldamccarthy.net), the metaphor of the Fifth Province re-presented a space that was connected to all those provinces of conversation that might be engaged with(in) but it was also simultaneously a space apart. It was therefore both a space of immanence and transcendence, immersion and observation. This means that we see it as holding the dualities of life while at the same time reaching beyond them. In our facilitation of the meditation groups and retreats the metaphor has come to stand for a space of transcendence and immanence, stillness, listening, attention and a compassionate detachment where the whole group experience becomes more than the sum of the individual participations. We see it as a welcoming space that invites a different point of viewing, circling around and about the rough passages and challenges on life's ocean. From the beginning it was a space that held together the apparent oppositions and dualities of life. It tried not to give way to either/or modes of linear thinking but invoked and embraced the both/and orientation of Batesonian and other complex systemic thinking and action. (Bateson, G., 1980; Bateson, N., 2017; Hoffman, 2002; McCarthy \& Simon, 2016; Wheatley, 2017) In the last twenty years, it has also become a space of meditation, reflection and contemplation. You may wonder about this direction but over the past years, based on our experience of meditating with groups, we have been seeing the resonance between what was happening in the therapeutic and consultation domains and what was occurring in the meditative contexts. 


\section{The Ocean in the Waves - Associated ideas}

One of the metaphors that has attracted us in our practices is that of "the Ocean in the Waves" (McCarthy 2017). The ocean is a metaphor for Unity and the waves are seen as those multiple diversities, which emerge on its surface given the different climactic contexts in our world. The ocean is water. Likewise, the waves, which rise and fall are also water. The underlying unity of the ocean is never destroyed by constant comings and goings of its waves. This metaphor highlights, for us, the concept and experience of what our spiritual teacher, Sri Vasudeva calls, Unity in Diversity and the One in the All. In the Tao Te Ching, the $6^{\text {th }}$ century BC, Chinese Daoist philosopher, Lao Tzu, refers to the "Dao" as that underlying principle of Life from which the myriad and diverse manifestations that create the multiple probable contexts for diversities in our world can emerge. (Mitchell, 1999) In the late nineteenth century, the Indian sage and carrier of Yoga to the United States, Swami Vivekananda (1895) pointed to a similar reality in his words that "unity" is self-evolving out of which everything comes. Across many of our spiritual traditions it is pointed out that everything in our Universe is always struggling to complete a circle as it were, to return to its experience of unity. In Zen this circle is left open for possibilities to enter. Allied to our own systemic field, both biologist, Humberto Maturana and physicist, llya Prigogine talk about autopoiesis, that self-creating capacity of living and social organisms to generate and regenerate creative processes of increasing complexity. (Maturana, 1970; Prigogine, 1980). More recently the feminist philosopher Donna Haraway (2016) has talked about the concept of sympoiesis (making with) rather than autopoiesis (self-making) in order to draw our attention towards the co-participatory process of creation. In our experience we would propose that at the first level of the process we co-create with others (sympoiesis). Then, as the resonance within the group builds another experience emerges and develops where the group become more than the sum of its parts as it were. It's as if the group develops a sense of a "larger self" and what emerges from this is often new and spontaneous (autopoiesis). In this way the process could be seen to be both sympoietic and autopoietic.

Social psychologist John Shotter (2008 in Simon et al., 2017) also talked about a similar process in the following way. He says, that in taking different positions at different times, we build a culture of group reflexivity and develop a shared mind. Mind, here, refers to the fluid, reflexive, formative activities going on between people. Perhaps it echoes Fleck's idea of a thought collective (1976). What if, for instance, that which in our everyday talk we call the exercise of "wisdom" and "judgement" has little to do with the exercise of a capacity or a disposition already in existence within an individual, but is much more to do with a process of innovation, improvisation, or creative emergence occurring within the activities of an individual within the context of a "thought collective". (Shotter, 2008 in Simon et al., 2017 p.13).

However, the experience of practising in a meditation group affords a different way of seeing the above descriptions of Haraway and Shotter. From our experience there is not only resonance on the social and verbal level but rather a communing within a "field" beyond thoughts, affiliations, projects and other such collectivities and connections? This field lies beyond the rational and social spheres and more in the sphere of a non-rational, non-socially constructed consciousness or awareness. It is a kind of "post-human" field. So, there is an encompassing of what Haraway and Shotter are speaking about, indeed such connections are vital and then there is the deepening into both the "core of being" in each one and in the collective. Neither the individual nor the collective is lost nor are they to the fore. It is not explainable within our rational parlance but can be known by its effects in our lives as we will show towards the end of this paper. Emergences of insight, possibilities and creative impulses occur - often similar to each other but unique at the same time. This is the hallmark of what we refer to as a Fifth Province Systemic Meditative Process. Our spiritual teacher, Sri Vasudeva has referred to 
it as Self in Leadership or Self as Leader where the "Self" of the group inspires. Family Systemic Therapist, Richard Schwartz has also referred to this capacity within us and between us also as "Self in Leadership" (Schwartz, 1999, Sri Vasudeva, 2001; McCarthy, 2014; Minogue, 2018)

\title{
A New Way Forward - a Paradigm of intra-connection!
}

\begin{abstract}
For spiritual freedom, a person needs to break away from this mechanical working of symbols, values, and labels into which awareness is fragmented and driven through life. . . Liquidating these knots releases the energy of awareness bound in them. Collecting this awareness and rerouting it into your Self is the key to this freedom. When all these labels and tags are removed, the world of phenomena will not impose its perception on you anymore.
\end{abstract}

\section{Amarananda Bhairavan, 2000, p.179}

When our daily and social constructed perceptions and conditionings are backgrounded then a stillness and silence can emerge not only within individuals in a meditating group but also in the collective or field of the group. What has been so interesting to us over the years is that this field does not only "operate" when we are together but also holds us together in a powerfully felt experience of connection, care and love when we are away from each other physically. There is a felt unity in spite of our diversity and geographical distance. There is no doubt that our world today needs a paradigm grounded in unity and intra-connection. It is our belief and hope that based on the practices and experiences, which we outline in this paper, that this paradigm will give birth to itself through all of us in our unique and diverse ways. Indeed, we would say that our paper has been one of the emergences from this co-created field. By both facilitating and being implicated in the processes we too have benefited in the ongoing experiences of inner peace and increasing balance and harmony in our daily lives.

Therefore, now, we see THAT as being our work to co-create the possibilities for all this to occur, both in our lives and in our world. As we have said, this effectively means that we move beyond a narrow or simplistic orientation of being entirely constituted by our thoughts, emotions and narratives. This does not mean that they do not have a potentially pervasive effect in shaping our lives and identities within our everyday phenomenal worlds. But it is not the whole "story". In this regard two Batesonian questions which begin to deconstruct the pervasiveness of our taken for granted thoughts and ways of seeing are useful. The first one comes from Gregory - Why do we think the thoughts that we think? The second comes from his daughter, Nora - How do I see the way that I see the way that I see?

When we ask these questions of ourselves, social and relational contexts become so important. Because, we can forget at the practice level (if not at the theory level) that frequently we can be nonconsciously reflexively constituted in and through our contexts and cultures. So, becoming conscious of them is an important orienting step. In this regard our systemic and social constructionist theories can help us to both examine and let go of these constructions and conditionings. In this work, we (and especially Imelda) have been inspired by the works of Gregory Bateson (1980), Humberto Maturana (1970, 1992), Ilya Prigogine (1980), the Milan team (Palazzoli et al., 1978, 1980), Gianfranco Cecchin (Cecchin et al, 1992; 1994), Harlene Anderson, (1997); Sheila McNamee, (2015) Gail Simon (Simon, 1998, 2010; Simon and Chard, 2014) together with our Irish poets, writers and artists. 
As starting premises, we also very much took on board, the ideas of Bateson (1980), Progogine (1980) and Maturana $(1970,1992)$ that, since we are self-evolving beings, we can be a self-evolving "cause" of our own co-evolutionary changes. We have the ability to create and co-create with others towards new possibilities. Nora Bateson (2016) has coined a new word for this process, Symmathesy, which highlights the expression and communication of interdependency and, particularly, contexts of complex mutual learning.

This kind of co-creation and mutual learning emerges spontaneously and uniquely from within the context and process of our relational dancing and moving together - our intra-action. Imelda has been calling this practice towards an emergent and evolving consciousness, Communion and Systemic Emergence (McCarthy, 2004) What we mean by Communion is that collective field of relationship, consciousness and wisdom that is co-created and set in motion when two or more meet in an openhearted resonant dialogue. So, it refers to an emergent sense of Presence and wisdom that is greater than the sum of our individual presences and yet enfolds them. We might call this a Systemic Self after the notions of Self as Leader referred to earlier. In our experience this Presence with its emergent wisdoms arises spontaneously and always magically from a deep resonant connection among diverse participants. Alongside, there are also frequent experiences of synergy, synchronicity, resonance, love and a feeling of lightness.

In such relationships we, as facilitators are never the primary doers per se. Futures might be imagined but not predicted with any certainty. We are not part of a linear sequence where we are in any way a "cause of change". Rather it is a circular engagement and process, which is catalytic, organic, mysterious and enlivening. This brings us back to our current imaginings for and experiences of our Fifth Province stance.

\section{Imagining the Fifth Province anew}

In 1999, Imelda met our spiritual teacher, Sri Vasudeva, an East Indian Trinidadian. Early in her relationship with him she was presenting on her work on Sexualised Abuse ${ }^{1}$ and he said, "The frame is too small". Initially thrown by the remark, she then realised that he was correct from a larger holistic way of seeing. The frame was too small. It was a problem led frame even though it included possibilities. After this she moved instead from a space in therapy that while it held all the dualities and dilemmas in any dialogue it also held a dis-position beyond them to a space of all possibilities, a space where all is perfect. When we use the term, dis-position we are referring to a movement between the positions presented in dialogue in a spirit of compassionate detachment by a facilitator. The term was first used by Seamus Heaney in the foreword to the Irish Journal, The Crane Bag which was edited by Irish Philosophers, Richard Kearney and Mark P Hederman. (Heaney, 1977)

The Milan team's idea that "the system is perfect", serves as a reminder to maintain a positive frame of appreciation that, given optimal contexts complex systems, will each find their own unique ways of being whole and healthy! We just need to understand how each unity works and co-create an observing system which is capable of re-calibrating itself and all of our relationships. This description of course includes all of us as professional facilitators working with unities we call couples, families, groups and organisations. You will remember that in their early work they always added a post session message with some kind of paradoxical injunction. Then they found that if they did not add this, the

\footnotetext{
${ }^{1}$ The use of the term "sexualised abuse" was informed by the work of Allan Wade and his colleagues in British Columbia, Canada. (Coates and Wade, 2007)
} 
family or family-professional systems seemed to auto-correct between the sessions. Imelda's hypothesis about this has always been that they activated a Batsonian "collective self" (Nacmanovitch, 1981, p.13) or Maturana's autopoietic process (1970) and the family wiggled to find their own problem-free harmony in those long spaced-out breaks between sessions characteristic of the Milan approach. When we practise the subtle art of not making a problem out of any part of our experience we can move into a profound recognition that perfection is always already there - even though we may not see it at first glance.

Following in the train of Sri Vasudeva's words about contracted frames, Imelda refocused many of her workshops, presentations and writings on what she called, the "Space of the Fifth Province" (McCarthy $2004,2010)$. As clients, supervisees, groups and later meditation groups and retreats were invited into this space, a kind of magic revealed itself. The experience was that we were moving more in the realm of Being rather than doing and she began to talk about the mutuality of the processes of inter-viewing, inter-acting and inter-being. And out of that We space, unexpected possibilities emerged. The more recent work of Karen Barad talks of intra-action which refers to all action that occurs within relational unities or systems. It bypasses any illusions of an inner/outer dichotomy within relationships and dialogues.

In our article, we are also offering these ideas and practices as possibilities for coming together anew and reclaiming the wisdoms of our wonderful systemic field. To do this, we will re-present reflections of our group members highlighting the experiences of co-construction from different vantage points within our meditation group. Initially, we were interested to find out, that if we were co-constructing and generating a space of systemic communion and then how might co-conversationalists describe the process. From past experience in the field of systemic practice, clients who had no education (apparently) in what methodologies were being used were also using mirror descriptions about the process we were jointly engaged in. To give you a little taste of what we have been talking about we will firstly present two examples of how this Space of the Fifth Province was experienced in therapy and supervision. Then we will go on to present an example from our meditation community. In the first excerpts, we have chosen words that refer to the space of the therapy, emergences and Presence. We think you will see the similarities and connections in the process as it is described from two different domains - therapy/supervision and a meditation group.

Reflections from a therapeutic context - space of therapy, emergences and presence.

"Therapy changed my life - my whole life, completely and permanently and I still haven't figured out how! It is not in any way tangible so it's hard to understand... A picture of my life opened up for me, which I never thought was even possible to see. .... The sense of it at the time was that this had come from another domain.... A space was held for me where it was possible for this to happen by itself. I couldn't comprehend what she was doing! I perceived she was doing nothing - and that is exactly how the magic happened! Because I now know a window was being held open for me to set myself free.

Reflections from a supervision context - stillness, emergence and presence.

"My overwhelming experience was of a space that was invitational, supportive, gentle, and with a sense of deep quietness. Stillness is perhaps how I would characterise the most striking aspect of Presence and it evokes for me the remarkable reliability of the process. It reminds me that when I attend to safety, 
when I am fully present in good faith, when I listen to and respond to the other, then the space that we can create together can have elements of the 'spiritual' a feeling of bringing forth more than who each can be of our own human potential." (Eustace, 2010)

From our points of view, we would propose that something akin to what one might call, meditative conversations were taking place in therapy and supervision. There was a strong focus on context and presence, which recursively triggered a more expansive experience and observing in us all. This observing included something that we seem not to talk much about in our field and that is the emergence of an auto-poietic collective wisdom (Bateson, 1980; Maturana, 1970, 1992). The field itself becomes a learning context and is so much greater than the sum of the individual contributions. When this happens, it is reported as magic or as happening by itself - a human murmuration? There is no sense of any prejudged or prescribed outcome, no one can claim exclusive doership and yet pragmatic and aesthetic happenings occur and emerge. The doing as it were emerges from our Being together beyond our diversities. There is a sense of oneness, a sense of Communion. We would suggest that these are not just spiritual ideas they are also systemic ideas and practices.

So, when we talk of spontaneous emergences, systemic communion, presence and murmuration we are also bringing to mind the notion of Gregory Bateson's, "collective self". (Nacmanovitch, 1982). We see this in his constant evocation of an ecology of mind where many participate within co-created, coevolving fields. (Bateson, 1978) Also, when we talk of a system, we are in no way talking about any kind of mechanical entity but about living, vibrant, breathing and juicy unpredictable co-evolutionary patterns of interaction where all participants within the complex ecology live and learn - including ourselves as facilitators (and/or therapists and supervisors).

We have been asking and exploring for some years now, "how we can use this kind of thinking, practice and consciousness more in our lives and work today?" If we think of our world, our Universe, as trying to struggle and wiggle its way back to more evolved and harmonious conditions in the face of social and environmental challenges (climate change, rising oceans, terrifying politics and so on) then we need to look for and co-create movements which are allied to those more positive attempts towards (co-)evolutionary harmony. Rollin McCraty, the director of HeartMath (an institute dedicated to researching coherence in and between groups at micro and macro levels of relationships) points out in his work that "social coherence, relates to the harmonious alignment between couples or pairs, family units, small groups, or larger organizations in which a network of relationships exists among individuals who share common interests and objectives" (McCraty, 2017, p.1). He goes on to say that a "high degree of social coherence is reflected by stable and harmonious relationships, which allows for the efficient flow and utilization of energy and communication required for optimal collective cohesion and action. Social coherence requires that group members are attuned and are emotionally connected with each other, and that the group's emotional energy is organized and regulated by the group as a whole." (McCraty, 2017, p.1). Over the years of our practice these types of relational experiences have been common reflections in our group.

\section{Towards a Fifth Province Sangha - building communities of Presence, Love and Emergence}

Now we want to share with you how we have been including this kind of individual and relational coherence or what we call a Fifth Province systemic meditative approach within the meditation group. The co-construction of this coherence is composed of several elements which we will outline below. The two elements we will pay particular attention to are meditation and sacred conversation. We are 
also proposing that these kinds of processes might be useful to all of us who work in therapeutic settings as we come together in small groups for the building of presence and support. As with the reflections from the contexts of therapy and supervision above, we will now share with you a composite of what those in our meditation group have to say about the process of our Being together. You will notice how systemic this is and how similar it is to the reports from therapy and supervision. Recently a visiting UK therapist, Nafeesa Suraya-Naz Nizami reported her experience of participating with us, as one where it was like "the group was tapping into a larger wisdom, something bigger"

What we describe below has come from our group members who from time to time are asked to share their experiences of participation in the group. Most of the time when we gather we number between ten and fifteen. The group has comprised of twelve women and three men. To show how the narrative flows we will lay out the experiences in a way that describes our preparations which are also and intrinsically included in our practices and then we will follow with members' descriptions of their experiences and "outcome" of the practices.

\section{Setting and preparing the context}

Comments from group members will appear in italics within quotations marks in the sections below.

When we come together, there are a number of factors, which facilitate the emergence of our group field as an expansive and creative entity:

\section{(1) The Facilitator}

The most important element of a Fifth Province Meditative Practice and Process would be for the facilitator to prepare themselves. There is the preparation of turning our attention inwards, to focus our minds and empty ourselves out as it were of particular ideas, prejudices and goals, to be open to what can emerge, to enter a state of appreciation and compassion and to be in the present moment. In that sense the facilitator is active (even if they may appear not to be). They are actually holding the space in the room and the group very strongly in love and possibility at the outset of the group. Also important for a facilitator is the practice of staying in the present moment in both their connection with the group and simultaneously focusing on the depth of silence and stillness within themselves. As we said, we do not see the facilitator as the sole agent of change, but rather it is (a) the Presence, or larger "Self" within the facilitator connected within the group which (b) when connected with its larger wisdom or Presence, (c) becomes the catalyst for change in the all. So, focusing on the quality of Presence within the facilitator and all participants seems to be a potent catalytic element for tuning into the larger group or field Presence.

\section{(2) The careful preparation and energising of the environment}

A number of ways to energise the space physically can be employed by lighting incense or candles. We can also envision the room in advance and send it blessings as it were from a place of silence and love within oneself. Meditations in the room can also be used to energise the room and indeed will over time. The preparation of the space embraces the subtle (mental emotional energetic) aspects alongside the physical. As one member of the group who was interviewed said: "This is a sacred space. It is a sacred space. And I am aware it is a sacred space; and the minute I step into it, it feels like a sacred space." 
(3) Taking time to come together at the start in (silent) meditation in order to take us deep within to the stillness and silence of the larger field of our group and context

We do this so that possibilities for experiencing our "inter-being", or group spirit, in the most profound way can emerge. We also endeavour to hold it beyond the meditation practice itself. The sense of a growing connection as the group centre together in a prepared space, occurs at different levels of consciousness: physical; emotional; mental, and spiritual. The subtlety of the process can be described thus: "The space itself takes over... So, the actual process of itself, is kind of mysterious. We have described it as like a whirlpool; it brings people into its circulation, if you like. People catch it!"

Once the process gets going as it were then there is no individual leader as such. Initially it does help to have somebody who is a strong conductor in that they know how to attune both inwardly and outwardly. When attunement occurs in the group there is a sense of relaxation of the body and also personal boundaries. People feel a greater coherence in both themselves and the group. And the more people who are cohering together strongly, then the rest of the group can also experience coming into that sense of coherence.

\section{(4) Trust}

The other thing is - we always trust the space. The space beyond the mind is a creative space of deepest wisdom and has also been known by many creative people, artists and poets, scientists and inventors. It is a space of all possibilities (McCarthy, 2004). Answers to life questions can arise spontaneously from within oneself and/or from any member of a group when the group is centred in coherence with each other. "There were things I needed to sort out, in life... that needed attention... I realise in looking at them, how much I have changed as a person! It is kind of a confidence... in that, I am happy: I am not looking at others for points of reference, in terms of how other people would handle things."

There is a trusting required; that when we open to the Spirit of the group, its greater wisdom will shine through us as we relinquish any control our mind endeavours to claim. "It is important to constantly do the practices of going within and trusting the Universe, or trusting the field, or trusting the situation that it will be okay... without any particular kind of form (so it is not a prayer)". The trust is in the process itself. "It is not an outer looking practice. It is more an inner looking practice, whether that is inside one's self or within the field of the group; and trusting that field to produce whatever is needed."

\section{Fifth Province Meditative Practices - Sacred Conversations}

Then, aspects from our meditative process can be brought into the group sacred conversation which follows, to further enhance the coherence within the group. The practices we use in this phase would be to remain in present moment awareness, to constantly challenge our social conditionings and constructs, to manage our mind and thoughts by focusing on the silence and stillness within ourselves and the group, to accept the other and listen with love and from the heart. Questions are created in such a way that they are open, and minimal in terms of intellectual knowledge required, to encourage participants to speak from their own deepest truth/silence - a re-sourcing from deeper Self.

We have both found is that the subtle aspects of the Fifth Province Meditative Process or Self as Leader process are indeed that; subtle. It has been demonstrated that it is not a matter of setting out to 
implement a particular process as such, but rather opening up to the possibility of it occurring; by promoting and practising the conditions in which it is most likely to occur. (McCarthy, 2004; Minogue, 2018)

The facilitator is also continually referencing whatever is said in the group, back to the rest of the group - inviting us into a larger whole (specific or general contexts of the conversation at hand). In our experience we have found that this facilitates both the group coming together as a unit, and then our expanding beyond the boundaries of a limited individual self. What we mean by this is that there are experiences that individuals have where they feel they are the only one in the room and that the group has become one with them with no separation into individuality of experience. We have found constantly, from these processes and our history of this way of being together that the process of experiencing oneness and unity can then appear to unfold effortlessly of itself. When we can listen without judgement, with love, acceptance and appreciation a space is opened for all to feel invited to share themselves in their intra-connection.

From feedback over the course of the group it is experienced that, what we call our Sacred Conversations are coming from a place of unconditional loving acceptance which allows each person the freedom to open up completely. Members have said that they feel empowered and moved to act from "who they truly are", thus contributing in a valuable way, towards opening up to a relational or group consciousness. So, there is an appreciation co-created in our group together with encouragement in the process of listening lovingly and compassionately, and from this "we can discover how powerful we all are when we come together."

All viewpoints are valuable and included, yet all are held lightly as they change and transform throughout our conversation. One person saying something, another picking it up and adding to it, shaped by all with curiosity and enthusiasm, and then suddenly something completely new and unforeseen may emerge! "Answers come out of nowhere."

To the delight of those in the group who observe this process, any member of the group can become the "vehicle" for these new insights and awarenesses to emerge spontaneously. "We all come from very different perspectives and places... but we are all very much one in the group... there is huge sharing that goes on, and there is, I feel anyway, just complete acceptance. It is non-judgemental... So, it is done from a place of... love, actually". It can seem that the wisdom has just appeared in the space and snowballed... and from this fresh awareness, many further creative solutions seem to arise.... "It does come in to my everyday life: it is in my family... They experience it... It is just because I am happier, because I am more settled... Because I am more even minded. And it is the same thing in my work probably, in my relationships at work... I do not feel quite so exposed or vulnerable. So, as we also have come to experience: "The process is about who we are individually and collectively. It is not so much about what we do...." Something "bigger" comes into the space... So that we then become more than the sum of the parts."

Deep in meditation we connect with both the transcendent and the immanent, the individual and the collective. In the latter we are intimately connected in the world around us. All traditions suggest that personal meditations are strengthened when practiced with a group, particularly over a long period. When we come together in groups there is a different quality as we develop a field (a context) that is greater than the sum of its elements. It is this latter co-creative possibility that has excited Imelda during her life as a systemic therapist and during the past twenty years in the context of meditation, the group and retreats. As will be seen from the reflections we are presenting in the paper, many of our meditation group would say that they have experienced transformations in their lives, in their 
families, in their work, in their communities through being part of the weekly group field and our longer (yearly) retreats.

\section{Group emergences from the dynamic-still space of a meditation group}

Now we will call on our group's voices in relation to this powerful systemic and spiritual practice and process. Such is the connection within the group that even for those who may be unable to attend they still are tuned to the group. All of the group have reported that they have had experiences of being supported by the group field during life challenges whilst being physically away from the group. Because of this, we have begun to open ourselves to the possibility that we can also support people in our world who are challenged by violence, huger, thirst, migration etc., our environment, animals and our oceans, rivers and lakes. We have adopted the term for this practice of Subtle Activism (Nicol, 2016).

\section{(i) Attunement when physically apart from the group:}

"reading your email has had the effect of bringing me to that space of unity, oneness and love"

"If I have to be away, I tune in, knowing it is the place I want to be. Its essence is love and nurturance, within a framework of deep spirituality - a still holding of self and other. This is crucial for me, the challenge to integrate that wider consciousness that resonates profoundly within me in my work outside the group."

\section{(ii) The meditation field - murmurations in silence}

"When I enter into the room, I can immediately feel a state of peace and calm and I feel a strong sense of resonance. When I become aware of others sharing the silence with me in the group, my field of awareness can shift in various ways. I feel like boundaries of form dissolve and fall away and there is so much lightness of being. There is an experience of sacred bondedness and communion - such light, peace and love".

"By silencing the mind and allowing myself to delve into the silence of the group, I have reached places of peace and energy that I didn't know existed inside of me. I can use the metaphor of matches perhaps. Lighting a single match on its own is like meditating in privacy. By putting the sulphur ends of numerous matches together, with one already ignited, the matches burst into flame with a multiplied intensity. This is what it feels like in the group. There is a greater intensity and stronger focus, bringing my own mind into the group's silence. In every aspect of my life I find ways that the group has helped me; to calm, to focus, to bring joy, to love! If nothing it has shown me how much endless love there can be in one small room, and therefore how much there is in the world".

"The meditations and chanting together bring a sense of togetherness, a sense of unity, a sense of connection, a sense of a palpable presence that arises when we sit and meditate together. Invariably there is deep joy and light-heartedness but also forged is a strong bond that provides support beyond those meetings". 


\section{(iii) Meditative Conversations}

"Our meditation group conversations, because of the similarities in the practices, are really a continuation of our meditation practice. These include staying in the present moment, listening with an open mind, having no judgment, staying open to all possibilities and not getting caught in the stories of our lives. This environment allows us to connect at the deepest level and invites us to act from that place. When performing tasks from this place the tasks seems effortless, yet a lot gets done. For me this is magical".

"This isn't about talking through it all... It is actually about the restoration that comes, from something that is bigger than that; and connecting in to something that is co-created; that doesn't involve going through the detail of all that is going on for me... But actually, surpasses all that... But it is held in a different way; that is tapping into something that is deeply nourishing.... and supportive; it is not about providing solutions. It is allowing us all to connect into that inner reserve or strength. That is a very powerful thing".

\section{Authors' Reflections}

The process of a Fifth Province Meditative Systemic Practice could be described as an evolving together without losing the individual and their experiences. We can experience both the individual and the collective simultaneously. "We are" and "I am" together as a flowing, evolving collectivity. There is no aloneness, there is oneness. We can feel orchestrated but without losing our individual sense of choice and agency. Listening to that kind of orchestration gives us a sense of life direction. It is in this experience that we can imagine ourselves as a kind of human murmuration. Our separation is dissolved and yet we do not lose our sense of our uniqueness in this intra-active experience.

Many of you who are reading this article and who meditate will have experienced that when we meditate together we co-create a more expansive field where our meditations feel deeper. When we come together in groups there is a different quality as we develop a field that is greater than the sum of its elements. In fact, while not losing our sense of who we are in the world we also lose our sense of an unconnected individuality. We experience instead our deep inter- and intra-connection(s). It is this latter co-creative possibility that has excited us, especially in recent years. As we have said above we have also been seeing that we can also engage in Subtle Activism (Nicol, 2016) in our world. This is achieved when an individual or a group holds themselves, another, others or groups who are challenged with poverty, violence, war, migration, climate change etc., our world, the environment in a heart space of love, compassion and healing.

We have witnessed first-hand the power of the practice over the years. For Imelda, it has also been a reminder of her early experiences in team's conferences held in the 1970's and 1980's where small groups of people in community triggered change at a larger social level of our therapeutic and national communities. Services and national associations sprang up all over the world as a result of this focused community and group inter-and intra-action. The systemic communities were making new theories and practice together and separately, locally and globally. It was a movement. In terms of our meditation community and as seen from the reflections, many of our members would say that they have experienced transformations in their lives, in their families, in their work, in their communities through being part of the weekly group and our longer retreats. Some have made national and international contributions which they feel are supported in the group 
We have seen how meditation enhances the possibilities for therapists to develop Presence, coherence, complex awareness, equanimity, compassion and detachment in their work and in their lives. In the exciting and challenging work of therapy there is no doubt that greater equanimity and calmness of being are essential for the wellbeing of our systemic community and can help us in the ongoing processes of contributing to organic systemic, dialogical and relational processes. Maintaining our equanimity in the face of extreme presentations and refraining from having any kind of purposive or pre-ordained commitment to particular outcomes has been one of the many gifts of meditation practices for us, the authors. As on ongoing process, we are continuing weekly to reflect on and develop the meditation and group processes illustrated in this paper. Who knows what will emerge next!

\section{Acknowledgement}

We are so grateful to our weekly meditation group partners (and especially to Denise Abell, Paul Abell, Margaret Daly, Aron Hegarty, Sorcha Hegarty, Tina Kelly, Pam Minogue, Lynda Spollan and Gina Whelan) who have generously facilitated us, through their participation as reflectors in this paper and also for supporting enthusiastically our writing project.

\section{References}

Anderson, Harlene (1997). Conversation, Language and Possibilities: a Postmodern Approach to Therapy. New York, NY: Basic Books.

Bhairavan, Amarananda (2000). Kali's Odiyya. York Beach, ME: Nicolas-Hays.

Bateson, Gregory (1978). Steps to an Ecology of Mind. London: Paladin.

Bateson, Gregory (1980). Mind and Nature: a necessary unity. New York, NY: E. P. Dutton.

Bateson, Nora (2016). Small Arcs of Larger Circles: Framing through other patterns. Axminster: Triarchy Press.

Byrne, Nollaig \& McCarthy, Imelda (2007). The Dialectical Structure of Hope and Despair: A Fifth Province Approach. In Flaskas, C., McCarthy, I. \& Sheehan, J. (Eds.) Hope and Despair in Narrative and Family Therapy: Reflections on Adversity, Forgiveness and Reconciliation. Hove/NY: Brunner Routledge.

Cecchin, Gianfranco; Lane, Gerry \& Ray, Wendal A. (1992). Irreverence: A strategy for therapists' survival. London: Karnac.

Cecchin, Gianfranco; Lane, Gerry \& Ray, Wendal A. (1994). The cybernetics of prejudices in the practice of psychotherapy. London: Karnac.

Coates, Linda \& Wade, Allan (2007). Language and Violence: Analysis of Four Discursive Operations. Journal of Family Violence, 22, 7, 511-522. https://doi.org/10.1007/s10896-007-9082-2

Eustace, Ruth. (2010). Reflections on Personal \& Professional. Development Process in the Supervisors Training Programme. Clanwilliam Institute, Dublin. (Unpublished)

Haraway, Donna, J. (2016). Staying with the trouble: Making kin in the Chthulucene. Durham, NC: Duke University Press.

Hoffman, Lynn (2002). Family Therapy an Intimate History. New York, NY: Basic Books.

Maturana, Humberto R. (1970). Biology of Cognition. Urbana, IL: University of Illinois Press. 
Maturana, Humberto R. \& Varela, Francisco J. (1992). The Tree of Knowledge: Biological roots of human understanding. Boston, MA: Shambala Publications.

Minogue, Jean (2018). Accompanied by Spirit: The Self as Leader Process in Spiritual Accompaniment. MA (Applied Spirituality) Dissertation. Dublin/Waterford: SpIRE/Waterford Institute of Technology.

Mitchell, Stephen (1999). Tao Te Ching. London: Francis Lincoln.

McCarthy, Imelda (2001). Fifth Province re-versings: the social construction of women lone parents' inequality and poverty. Journal of Family Therapy, 23, 3, 253 - 277. https://doi.org/10.1111/1467-6427.00183

McCarthy, Imelda (2004). The Fifth Province and Spirituality: Co-Creating a Sacred Space of Love in Therapy Conversations. In (Ed.) Madigan, S., Therapy from the Inside Out. Vancouver: Yaletown Family Therapy Press.

McCarthy, Imelda (2010). The Fifth Province: Imagining a Space of Dialogical Co-Creations! Context, Dec, 6-11. McCarthy, Imelda (2014). Self as Leader and Fifth Province. Blue Star's Leader's Retreat. Loenen: Blue Star Holland.

McCarthy, Imelda (2017). The Ocean in the Waves: Unity in diversity and the implications of a Fifth Province Approach in complex systems. Metalogos Systemic Therapy Journal, 31.

McCarthy, Imelda \& Simon, Gail (2016). Systemic Therapy as Transformative Practice. Farnhill: Everything is Connected Press.

McCraty, Rollin (2017). New Frontiers in Heart Rate Variability and Social Coherence Research: Techniques, Technologies, and Implications for Improving Group Dynamics and Outcomes. Frontiers of Science https://doi.org/10.3389/fpubh.2017.00267

McNamee, Sheila (2015). Radical Presence: Alternatives to the Therapeutic State. European Journal of Psychotherapy \& Counselling, 17, 4, 373-383. https://doi.org/10.1080/13642537.2015.1094504

Nacmanovitch, Stephen (1982). Gregory Bateson: Old Men Ought to be Explorers. Coevolution Quarterly, 17, 2, 113-118. http://cat4chat.narod.ru/files/stephen_nachmanovitch_about_bateson.pdf

Nichol, David (2016). Subtle Activism: The Inner Dimension of Social and Planetary Transformation. New York, NY: State University of New York (SUNY) Press.

Prigogine, Ilya (1980). From Being to Becoming. San Francisco, CA: W. H. Freeman.

Shotter, John (2008). Notes on Acting from within a "Thought Collective" (Fleck, 1979) - Moving on from 'after the fact' thinking to 'before the fact' thinking. www.johnshotter.com

Simon, Gail (1998). Incitement to Riot? Individual Identity and Group Membership: Some Reflections on the Politics of a Post-Modernist Therapy. Human Systems: Journal of Systemic Consultation and Management, 9, 1, 33-50. https://bit.ly/2tlkBac

Simon, Gail (2010). Self Supervision: Surveillance and Transgression. Journal of Family Therapy. 32, 3, 308-325. https://doi.org/10.1111/j.1467-6427.2010.00505.x

Simon, Gail; Kebbe, Lisen; Olsson, Ann-Margreth \& Vedeler, Anne Hedvig (2017). Creating Dialogical Pop-Up Installations in Public Spaces. Murmurations: Journal of Transformative Systemic Practice, 1, 1, 1-17. https://doi.org/10.28963/1.1.2

Simon, Gail \& Chard, Alex (2014). Systemic Inquiry: Innovations in Reflexive Practice Research. Farnhill: Everything is Connected Press.

Schwartz, Richard C. (1999). Releasing the Soul, Psychotherapy as a Spiritual Practice. In Walsh, F. (Ed) Spiritual Resources in Family Therapy. New York, NY: The Guilford Press. 
Vasudeva, Sri (2001). The Self as Leader. Blue Star Holland: Loenan.

Vasudeva, Sri \& McCarthy, Imelda (2002). The Messenger is the Message: Spirituality and Family Therapy.

Feedback, 9 , 1, 2-9.

Vasudeva, Sri \& McCarthy, Imelda (2003). Budbararen ar budspkapet: Andlighet och systemisk familjeterapi. Svensk FamiljeTerapie, 14, 2, $32-45$.

Vivekananda, Swami (1895). The Complete Works of Swami Vivekananda, Vol 7 Inspired Talks. Transcribed by S.E. Waldo (Sunday July 14).

https://en.wikisource.org/wiki/The_Complete_Works_of_Swami_Vivekananda/Volume_7/Inspired_Talks/Sun day,_July_14

Wheatley, Margaret, J. (2017). Who do we choose to be? Facing reality, claiming leadership, restoring sanity. Oakland, CA: Berrett-Koehler Publishers.

\section{Bios}

Imelda McCarthy, PhD, has been in the Family Therapy and Systemic field for most of her life as a therapist, trainer and supervisor. She was also an academic in the social sciences over twenty-five years at University College Dublin. She has published and presented internationally since 1983 and her work has been translated into nine languages. Over the last twenty years, Imelda has led a meditation group in her home in Dublin. She was spiritual director of a meditation organisation (Blue Star Ireland) for many years and is a member of Spiritual Directors International (SDI).

URL: imeldamccarthy.net

Email: imeldamccarthy46@gmail.com

Jean Minogue, MA, holds a Master of Arts Degree in Applied Spirituality and Certificate in Spiritual Accompaniment. She works as a Spiritual Counsellor in private practice and is on the Spiritual Accompaniment panel for the Waterford Institute of Technology/Spire Institute's MA in Applied Spirituality in Dublin. She has practised and worked alongside Imelda for ten years. Jean is an Associate member of the All Ireland Spiritual Guidance Association and member of Spiritual Directors International.

\section{Citation}

McCarthy, Imelda \& Minogue, Jean (2019). The Fifth Province Approach as a Systemic Meditative Practice. Murmurations: Journal of Transformative Systemic Practice, 2, 2, 55-69. https://doi.org/10.28963/2.2.6 